\title{
TO TESTING OF STEEL FIBRE REINFORCED CONCRETE AT ELEVATED TEMPERATURE
}

\author{
Vadims Goremikins ${ }^{\mathrm{a}, \mathrm{b}}$, Lukas Blesak ${ }^{\mathrm{b}}$, Josef Novak ${ }^{\mathrm{c}}$, Frantisek Wald ${ }^{\mathrm{a}}$ \\ ${ }^{a}$ Czech Technical University in Prague, Department of Steel and Timber Structures, Prague, Czech Republic \\ ${ }^{b}$ Riga Technical University, Institute of Structural Engineering and Reconstruction, Riga, Latvia \\ ${ }^{c}$ Czech Technical University in Prague, Department of Concrete and Masonry Structures, Prague, Czech Republic
}

\begin{abstract}
Addition of steel fibres improves properties of concrete. The lack of information considering tensile and post cracking behaviour of SFRC at elevated temperatures is an obstacle on the wide use of this composite material. This work presents an experimental study of steel fibre reinforced concrete subjected to high temperature. Compressive strength, split tensile strength and ultimate bending strength were evaluated. The specimens were heated by ceramic heaters and then repacked for testing.
\end{abstract}

Keywords: temperature distribution, elevated temperature, four-point bending test, compressive and tensile tests.

\section{INTRODUCTION}

The research presented herein leads to a proper description of SFRC behaviour under the actions of elevated temperature and understanding its behaviour in specific conditions. A proper material definition of SFRC makes it applicable not only by scientists but also by designers (Sukontasukkul et al. 2010) in the civil engineering practice. Making the SFRC material parameters applicable in civil engineering enables to construct more durable and cost competitive structures (Salehian et al. 2014). Several models of post-crack behaviour of SFRC have been developed, whilst new materials models are still being developed (Meskenas et al. 2014; Gribniak et al. 2013).

In spite of several advantages of SFRC for the enhancement of the sustainability, load carrying capacity, and ductility of structures, there is still not sufficient knowledge considering tensile and post cracking behaviour of SFRC at elevated temperatures due to fire. The behaviour of SFRC concrete in compression at elevated temperature could be assumed to be identical to plain concrete and is described in a number of researches (Fraternali et al. 2011, Fike, Kodur 2011) so as in the design codes. This paper is focused on describing the behaviour of SFRC in tension at elevated temperature where especially fibres are of an essential importance. Experimental data reached so far are limited to several mixtures of fibre content, fibre type, concrete class and other boundary conditions (Holschemacher et al. 2010; Caggiano et al. 2012). In order to reach reliable data, proper experimental measurement needs to be exact, all the possible mistakes need to be limited to minimum, maximal homogeneity in the SFRC mixture, temperature loading and other need to be focused on. Different heating and testing methods were applicable by research teams (Dugenci et al. 2015, Kim et al. 2015).

This research is a continuation of the previous one based on numerical modelling of SFRC behaviour, whilst all the data gained from the experiment were parallel compared to the ones reached by modelling, taken from the reference and other literature.

In this paper, experimental method on investigation of SFRC in elevated temperatures is described; other numerical data and reliable results will be published soon.

\section{HEAT TRANSFER TEST}

As an important part of the research, concrete specimen heating procedure should be developed. The aim of this task is to define a proper heating time period necessary for specimen reaching 
intended temperature and temperature distribution inside specimen is close to uniform. A special system consisting of a control machine Mannings HTC $70 \mathrm{~kW}$, ceramic heaters and thermocouples (Fig. 1) was used for the heating process. The heat transfer test was performed on a pilot cube 150x150x150 mm. Three $75 \mathrm{~mm}$ long holes for the thermocouples were drilled to monitor temperatures in the centre of the cube and $10 \mathrm{~mm}$ from edges. The prepared specimen was covered by two ceramic heaters which were in direct contact with the specimen. High temperature resistant glass wool insulation thermo-box was created to ensured heat accumulation and fix position of the heaters. The temperature was controlled inside the specimen, on the surface of heaters and on the surface of thermos-box (Fig. 2).
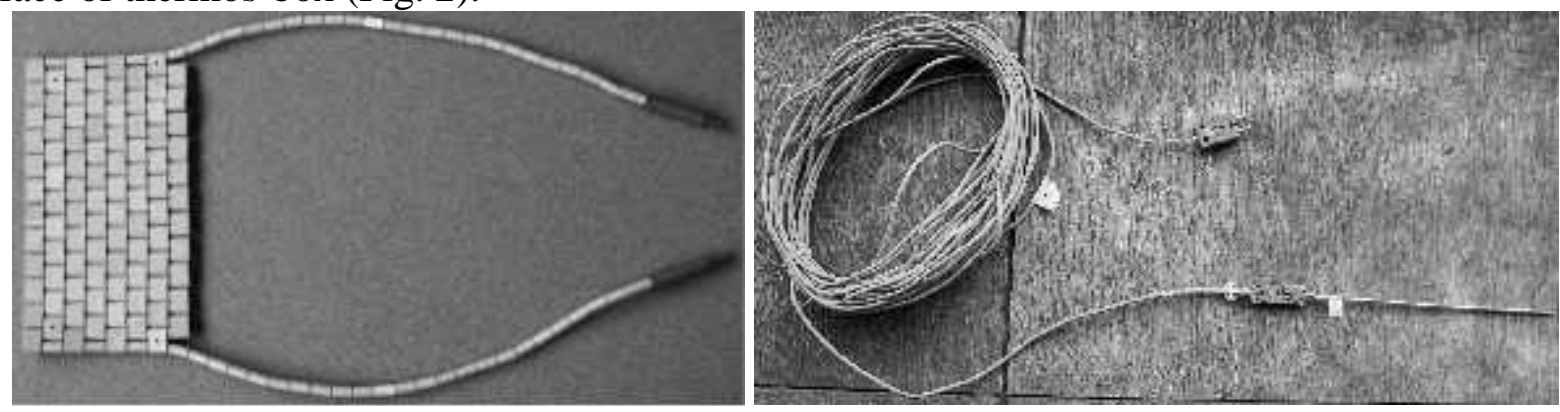

Fig. 1. Ceramic heater and K-type thermocouple
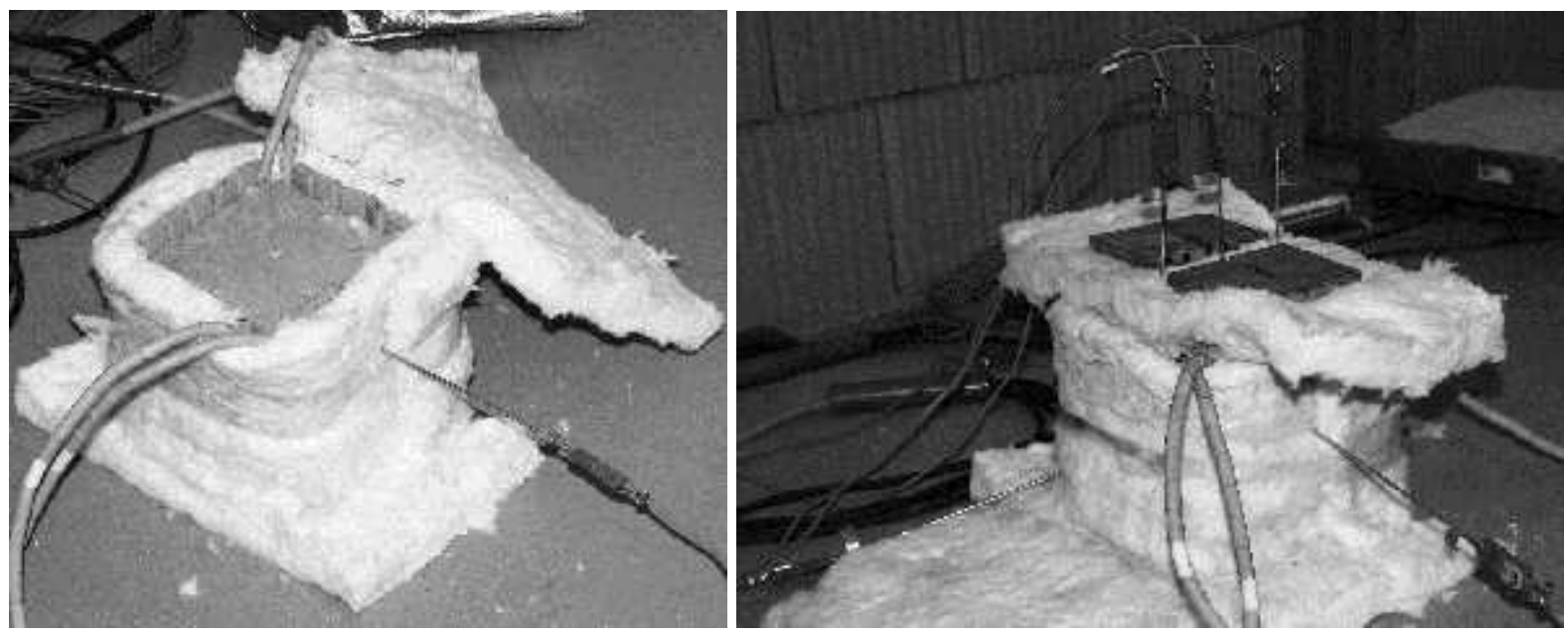

Fig. 2. Testing process of pilot cube with aim to obtain temperatures inside the cube

The ceramic heaters was heated up to $650{ }^{\circ} \mathrm{C}$ by the speed $1000{ }^{\circ} \mathrm{C}$ per hour. The process of heating as well as the temperature distribution in the specimen in time do not show any significant irregularities (Fig. 3). The temperature on the surface of the ceramic heaters linearly increased up to the temperature $650{ }^{\circ} \mathrm{C}$ in almost 40 minutes since the start of the heating process. Then the temperature of the heaters was kept constant until the temperature $600{ }^{\circ} \mathrm{C}$ was reached in the centre of the specimen. The obtained necessary heating time is equal to 3 hours and 25 minutes, then the specimen was ready for testing. After this phase the heating process was stopped and thereby the specimen started being cooled. It is important to mention that the specimen was removed from the thermo-box using fireproof gloves, repacked in a new glass wool and placed on steel plates with insulation layer on them. The intention of this process was to simulate the steps when the heating process stops and compressive and split tension test is conducted on a heated specimen. During cooling it is evident that the decrease in temperature on the specimen surface is more significant than in its core. Based on the results the maximum allowable time period for the static testing was determined in order to avoid the excessive loss of temperature of the specimen. 


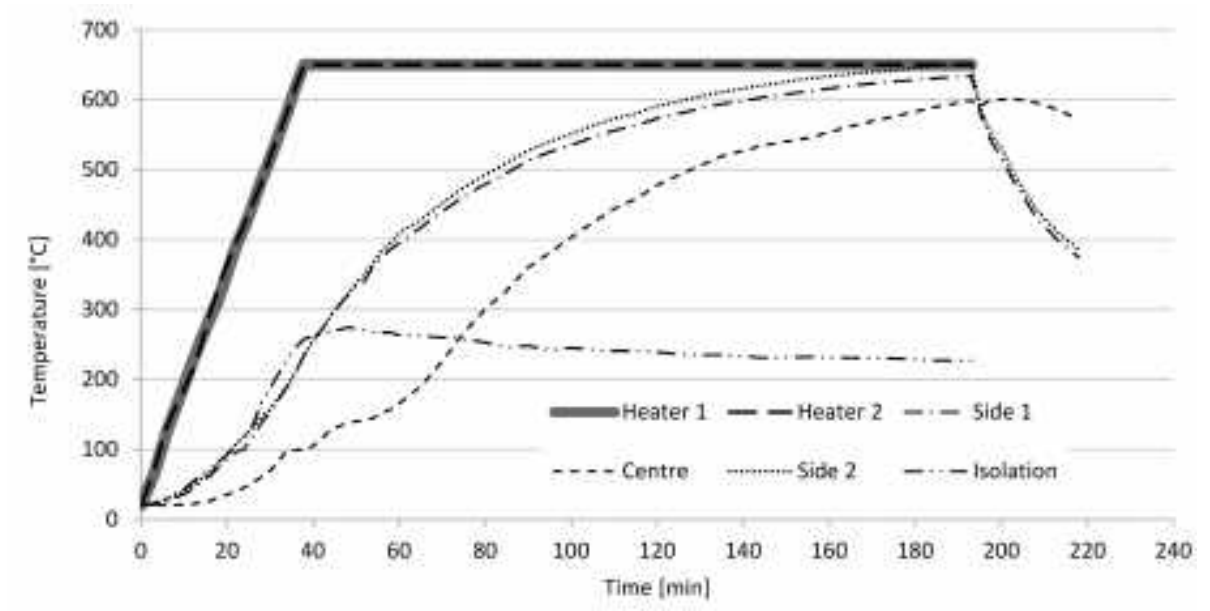

Fig. 3. Heat transport during heating process

\section{STATIC LOADING TESTS}

\subsection{Concrete composition and test specimens}

Fibre reinforced concrete FRC with strength classified as C45/55 was used for the static loading tests. This mixture consists of widely-used and available components, listed in Table 1. Polypropylene fibres were added to prevent concrete from spalling (Sideris et al. 2009).

The four point bending test was performed on beams notched in the mid-span. Using the beams with a notch leads to localizing the first flexural crack position, which's development was one of the main subjects of the performed test. Overall, there were 11 beams tested under various temperature conditions. The static compression test and split tension test of FRC were performed on cubes which were cut of spare prisms using a diamond saw.

Table 1. Composition of the tested steel fibre reinforced concrete

\begin{tabular}{|l|c|}
\hline \multicolumn{1}{|c|}{ Composition } & Content $[\mathrm{kg} / \mathrm{m} 3]$ \\
\hline CEM I 42,5R Mokrá & 330 \\
\hline Aggregate 0/4 mm Suchdol & 948 \\
\hline Aggregate 8/16 mm Nemojov & 669 \\
\hline Addition of fly ash Mělník & 140 \\
\hline Addition ViscoCrete & 3.96 \\
\hline Water & 190 \\
\hline Steel fibre HE 75/50 Arcelor & 70 \\
\hline Polypropylene fibre & 1.5 \\
\hline
\end{tabular}

\subsection{Compression test of concrete}

In compliance with CSN EN 12390-3:2012 the static loading test was conducted on the cubes dimensioned $150 \times 150 \times 150 \mathrm{~mm}$ under $20^{\circ} \mathrm{C}, 400^{\circ} \mathrm{C}$ and $600^{\circ} \mathrm{C}$. Tests were performed on overall 12 specimens. The whole set was divided into three groups based to the temperature of the particular specimen during the test. The specimens tested under elevated temperature were heated up to the intended temperature by the procedure used during the test of heat transport. The specimens were wrapped by the ceramic heaters first and then placed into a thermo-box made of glass wool (Fig. 4). Thermocouples were located on the ceramic heaters surface with the aim to record temperature during the heating. The time period of heating determined based on the heat transport test was 3 hours and 25 minutes. After the intended temperature was uniformly distributed all over a specimen the compression test was performed in a testing machine Inova 200F. In case of the heated specimens it was essential to keep to the testing time in order to avoid their excessive cooling. The compression test was deformation-controlled as $0.02 \mathrm{~mm} / \mathrm{sec}$ in the range of deformation $0-7 \mathrm{~mm}$ 
and $0.1 \mathrm{~mm}$ for the deformation bigger than $7 \mathrm{~mm}$. The force and deformation were parallel recorded during the test. The obtained data was used for creating load-displacement diagrams which describe the behaviour of the specimens. Particular diagrams figure the peak force and postcracking behaviour of the subjected FRC mixture.

\subsection{Split tension test}

The split tension test was performed on cubes 150x150x150 mm in compliance with CSN EN 12390-6: 2010. Altogether 12 specimens were tested under the actions of $20^{\circ} \mathrm{C}, 400^{\circ} \mathrm{C}$ and $600^{\circ} \mathrm{C}$ temperature. The subjected cubes were also divided into three groups. Two of them were tested under elevated temperature so it was necessary to heat some specimens up following the procedure used during the heat transport test. When the intended temperature was reached and uniformly distributed all over a specimen, the split tension test was performed. It was essential to keep the testing time under 15 minutes in order to avoid the excessive loss of temperature on the specimens. The test performed in the testing machine Inova $200 \mathrm{~F}$ was deformation-controlled as $0.02 \mathrm{~mm} / \mathrm{sec}$ in the range of deformation $0-7 \mathrm{~mm}$ and $0.1 \mathrm{~mm}$ for the deformation bigger than $7 \mathrm{~mm}$.

\subsection{Four point bending test}

The four-point bending test was conducted on notched prisms with the aim to obtain SFRC material behaviour including its peak and post cracking strength. The prisms 700x150x150 mm have a notch $48 \mathrm{~mm}$ deep and $4.6 \mathrm{~mm}$ wide located in their mid-span. The load is applied in the distance $100 \mathrm{~mm}$ from the mid-span on each side through a steel frame. The support distance equals $600 \mathrm{~mm}$. The tests of the prisms were performed under ambient $\left(20^{\circ} \mathrm{C}\right)$ and elevated $\left(400^{\circ} \mathrm{C}\right.$ and $\left.600^{\circ} \mathrm{C}\right)$ temperatures when four prisms of the whole set were used for each temperature. The tests were driven by displacement applied to a specimen through a hydraulic jack. The machine recorded the displacement and force. The crack opening displacement was picked up by a high speed camera Allied Vision Prosilica GT 200 with the speed 53.7 fps (Fig. 4) which monitored the position of two points marked on the specimen by high temperature resistant paint. The mutual distance of the points were continuously monitored and recorded during the experiments. The marks were located $1 \mathrm{~mm}$ above the peak of the notch and the initial horizontal distance between them was $50 \mathrm{~mm}$. The camera used the software Mercury RT 2.3.

In the preparation phase, a notch was cut and then all the prisms were measured and weighted. The dimensions of the prisms were determined in three positions with the precision $0.01 \mathrm{~mm}$. The average values were used for a further evaluation. During the four point bending test a loading force was applied through a hydraulic jack which also recorded the obtained data together with the high speed camera. These two measurements were connected together so there were received parallel outputs.

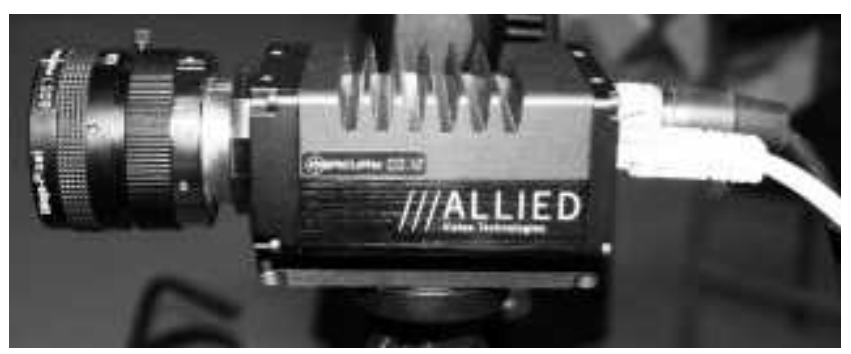

Fig. 4. High speed camera Allied Vision Prosilica GT 2000

For the heating process five electrical ceramic heaters were used. Two of them were installed at the bottom and three at the top of each prism. The temperature of the specimens was controlled by four thermocouples attached to the specimen surface. During the heating process as well as the static test the prisms were wrapped by glass wool insulation (Fig. 5) in order to eliminate thermal losses. To heat the specimens up to the intended temperature took four hours (Bednar et al. 2013). The accuracy and suitability of the heating process was firstly verified during the heat transfer test 
conducted on a pilot cube. The heat transfer test showed that after four hours of heating the temperature was constant both in the core and on the surface of the heated specimen.
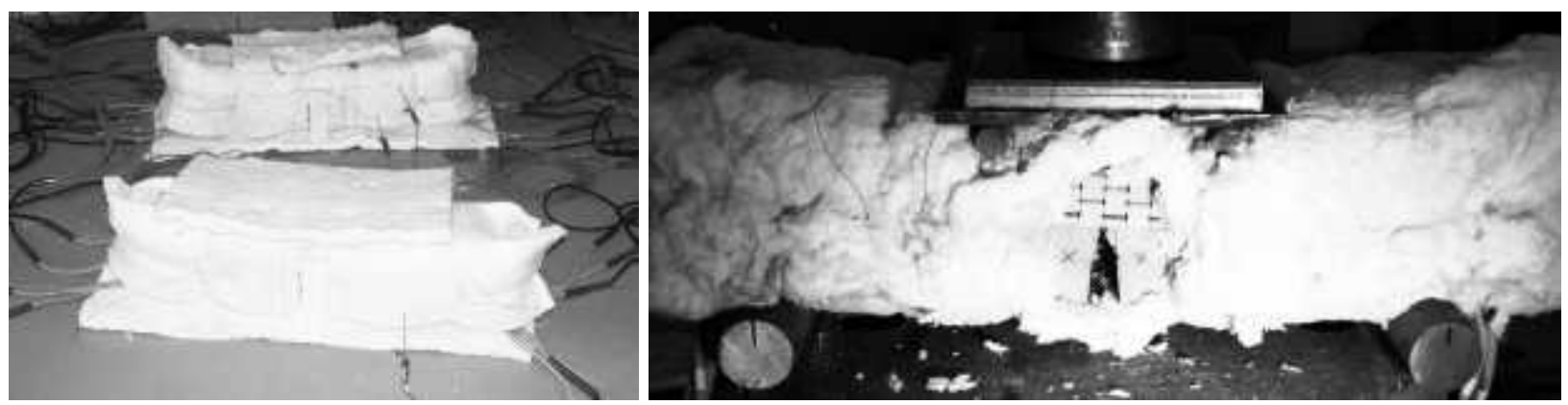

Fig. 5. Prism specimens during heating (left) and testing (right) process

Afterwards the four point bending test was performed on the prepared specimens heated up to intended temperature. The steel supports as well as the steel loading frame were installed directly on the tested prisms. Thereby the concrete-steel contact excluded any unexpected deformation caused by the thermal insulation being compressed.

The propagation of cracks, their amount, direction and occurrence were diverse for each prism and thus hardly predicted. This phenomenon is mainly caused by non-homogeneity of the tested material, particularly the number of fibres right above the notch has significant influence on crack occurrence. The obtained dependence of concrete temperature on compression and tension strength and bending force decrease is shown in Fig. 6.

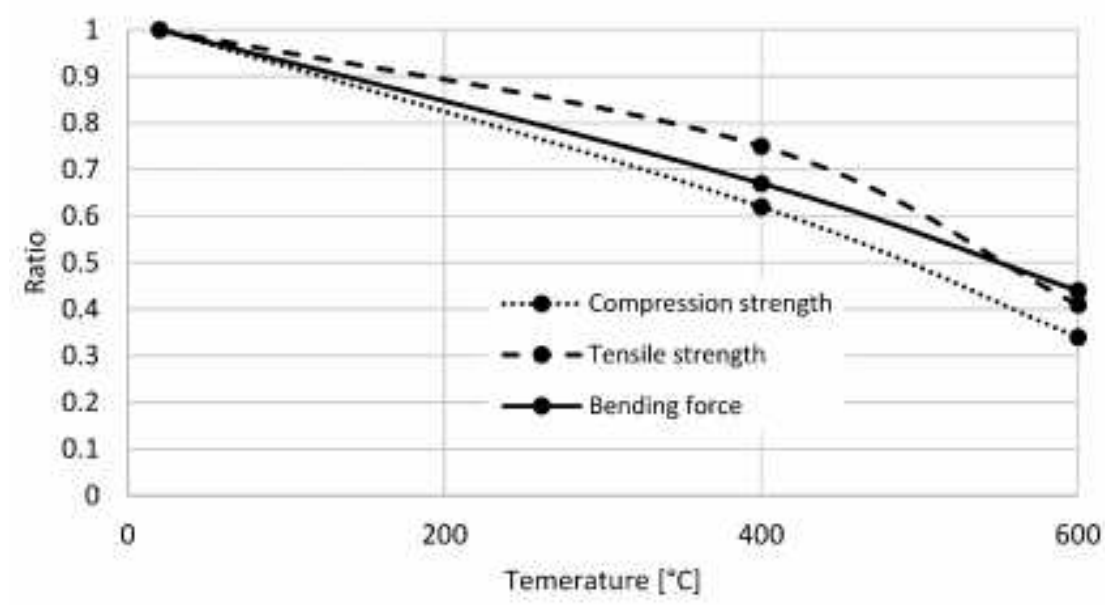

Fig. 6. The dependence of concrete temperature on compression and tension strength and bending force

\section{CONCLUSIONS}

Steel fibre reinforced concrete was experimentally tested under ambient and elevated temperatures. The developed testing procedure includes determining heating time by pilot cube testing and measuring temperatures inside the concrete, testing concrete cubes in compression and split tension and notched prisms in four point bending at ambient and elevated temperatures. The developed testing procedure could be used for determination of material properties under elevated temperatures. Compressive strength of SFRC is reduced by $38 \%$ and by $66 \%$, tensile strength is reduced by $25 \%$ and $59 \%$, and ultimate bending force is reduced by $33 \%$ and $56 \%$ in case of $400^{\circ} \mathrm{C}$ and $600^{\circ} \mathrm{C}$ comparing with ambient temperature, respectively. Detailed numeral and graphical results and its application for advanced and simple prediction models are under preparation for further publication. 


\section{ACKNOWLEDGEMENT}

This publication was supported by the European social fund within the framework of realizing the project ,Support of inter-sectoral mobility and quality enhancement of research teams at Czech Technical University in Prague“, CZ.1.07/2.3.00/30.0034.

This publication was prepared under grant of Grant Agency Czech Republic Models of steel and fibre concrete composite columns exposed to fire, GACR 15-19073S.

\section{REFERENCES}

Bednář, J.; Wald, F.; Vodička, J.; Kohoutková, A. 2013. Experiments on membrane action of composite floors with steel fibre reinforced concrete slab exposed to fire. Fire Safety Journal 59: 111-121.

Bencardino, F. 2013. Mechanical Parameters and Post-Cracking Behaviour of HPFRC according to ThreePoint and Four-Point Bending Test. Advances in Civil Engineering 2013: 1-9.

Caggiano, A.; Cremona, M.; Faella, C.; Lima, C.; Martinelli, E. 2012. Fracture behaviour of concrete beams reinforced with mixed long/short steel fibres, Construction and Building Materials 37: 832-840.

CSN EN 12390-3: 2012. Testing hardened concrete - part 3: Compressive strength of test specimens. UNMZ, Prague.

CSN EN 12390-6: 2010. Testing hardened concrete - part 6: Tensile splitting strength of test specimens. UNMZ, Prague.

Dugenci, O.; Haktanir, T.; Altun, F. 2015. Experimental research for the effect of high temperature on the mechanical properties of steel fiber-reinforced concrete, Construction and Building Materials 75: 82-88.

Fike, R.; Kodur. V. 2011. Enhancing the fire resistance of composite floor assemblies through the use of steel fiber reinforced concrete. Engineering Structures 33(10): 2870-2878.

Fraternali, F.; Ciancia, V.; Chechile, R.; Rizzano, G.; Feo, L.; Incarnato, L. 2011. Experimental study of the thermo-mechanical properties of recycled PET fiber-reinforced concrete. Composite Structures 93: 23682374.

Gribniak, V.; Cervenka, V.; Kaklauskas, G. 2013. Deflection prediction of reinforced concrete beams by design codes and computer simulation, Engineering Structures 56: 2175-2186.

Holschemacher, K.; Mueller, T.; Ribakov, Y. 2010. Effect of steel fibres on mechanical properties of highstrength concrete, Materials and Design 31(5): 2604-2615.

Kim, J.; Lee, G.; Moon, D.Y. 2015. Evaluation of mechanical properties of steel-fibre-reinforced concrete exposed to high temperatures by double-punch test. Construction and Building Materials 79: 182-191.

Meskenas, A.; Gribniak, V.; Kaklauskas, G.; Arnautov, A.K.; Rimkus, A. 2014. Simplified technique for constitutive analysis of SFRC, Journal of Civil Engineering and Management 20(3): 446-453.

Salehian, H.; Barros, J.A.O.; Taheri, M. 2014. Evaluation of the influence of post-cracking response of steel fibre reinforced concrete (SFRC) on load carrying capacity of SFRC panels. Construction and Building Materials 73: 289-304.

Sideris, K. K.; Manita, P.; Chaniotakis, E. 2009. Performance of thermally damaged fibre reinforced concretes, Construction and Building Materials 23: 1232-1239.

Sukontasukkul P.; Pomchiengpin, W.; Songpiriyakij, S. 2010. Post-crack (or post-peak) flexural response and toughness of fibre reinforced concrete after exposure to high temperature, Construction and Building Materials 24: 1967-1974. 